\title{
Gestão e aualiação de sistemas municipais de ensino público
}

\author{
Management and evaluation of municipal public education systems
}

\section{Gestión y evaluación de sistemas municipales de educación pública}

\author{
Raimunda Maria da Cunha Ribeiro' \\ Universidade Estadual do Piauí, campus de Corrente, Curso de Pedagogia, Professora. \\ https://orcid.org/0000-0001-6196-731X
}

Resumo: 0 campo da educação tem sido marcado pela divulgação de estatísticas vindas da realização de avaliação em larga escala, impactando, assim, no modelo de gestão nos sistemas de ensino. Este estudo, pois, tem como principal objetivo averiguar se a autonomia institucionalizada no sistema municipal de ensino tem impacto nos resultados da avaliação em larga escala, tomando como referência o IDEB, no âmbito de estado do Piauí. A metodologia adotou atributos da abordagem qualitativa e quantitativa. A técnica de coleta de dados foi a análise documental: conjunto de leis de criação dos sistemas municipais de ensino no Piaúi; resultado oficial das avaliações em larga escala dos municípios piauienses. Quanto à técnica de análise dos dados, adotamos os princípios da análise de conteúdo, segundo as orientações de Bardin (2009). Os dados da pesquisa nos possibilitaram compreender que: o estado do Piauí traz consigo sérias limitações econômicas e educacionais; no conjunto das 97 leis analisadas, apenas 04 fazem referência ao processo nacional de avaliação; o IDEB do Piauí, considerando as redes municipais de ensino público nos anos iniciais, está na casa de 4,6; numa frequência de 6,25\% dos municípios, identificamos IDEB igual ou superior a 6,0 nos anos iniciais. E assim, a gestão dos sistemas de ensino vai se prestando ao mesmo papel do Estado avaliador, ou seja, da ideologia neoliberal à gestão do ensino e às políticas de avaliação.

Palavras-chave: Gestão democrática. Avaliação educacional. Sistemas municipais de ensino.

Abstract: The field of education has been marked by the diffusion of statistics of large-scale evaluation, impacting on the management model in educational systems. This study, therefore, has as main objective to find out whether institutionalized autonomy in the municipal education system has an impact on the results of large-scale evaluation, taking IDEB as a reference, within the state of Piauil. Methodology has adopted the attributes of the qualitative and quantitative approach. The technique of data collection was the analysis of documents: a set of laws for the creation of

Doutora em Educação pela Pontifícia Universidade Católica do Rio Grande do Sul; Mestre em Educação pela Universidade Católica de Brasília. 
municipal education systems in Piaul; official result of the large scale evaluations of the municipalities of Piaui. Regarding the data analysis technique, we adopted the principles of containment analysis, according to Bardin's guidelines (2009). The data from research allow us to understand that: the state of Piaui has serious economic and educational limitations; Of the 97 laws analyzed, soil 4 refers to the national assessment process; The IDEB of Piauí, considering the municipal public escuela systems in the first years, is around 4.6 ; In a frequency of $6.25 \%$ of the municipalities, we identified IDEB equal to greater than 6.0 in the initial years. Thus, the management of educational systems lends itself to the same role that the evaluative state decides from neoliberal ideology to educational management and evaluation policies.

Keywords: democratic management; educational evaluation; municipal education systems.

Resumen: El campo de la educación ha estado marcado por la difusión de estadísticas de la evaluación a gran escala, impactando así el modelo de gestión en los sistemas educativos. Este estudio, por tanto, tiene como objetivo principal conocer si la autonomía institucionalizada en el sistema educativo municipal tiene un impacto en los resultados de la evaluación a gran escala, tomando como referencia al IDEB, dentro del estado de Piauí. La metodología adoptó los atributos del enfoque cualitativo y cuantitativo. La técnica de recolección de datos fue el análisis de documentos: conjunto de leyes para la creación de sistemas de educación municipal en Piauí; resultado oficial de las evaluaciones a gran escala de los municipios de Piaui. Con respecto a la técnica de análisis de datos, adoptamos los principios del análisis de contenido, de acuerdo con las pautas de Bardin (2009). Los datos de la investigación nos permitieron comprender que: el estado de Piauí conlleva serias limitaciones económicas y educativas; De las 97 leyes analizadas, solo 4 se refieren al proceso de evaluación nacional; El IDEB de Piauí, considerando los sistemas de escuelas públicas municipales en los primeros años, es de alrededor de 4.6; En una frecuencia de $6.25 \%$ de los municipios, identificamos IDEB igual o superior a 6.0 en los años iniciales. $Y$ así, la gestión de los sistemas educativos se presta al mismo papel que el estado evaluador, es decir, desde la ideología neoliberal hasta la gestión educativa y las políticas de evaluación.

Palabras clave: Gestión democrática. Evaluación educativa. Sistemas educativos municipales.

Recebido em 5 de maio de 2020

Aceito em 28 de outubro de 2020

\section{INTRODUÇÃO}

0 princípio da gestão democrática da educação está definido na Constituição de 1988 (art. 206), e também na LDB n. 9.394/96 (art.14), a qual destaca a definição das normas da gestão democrática nos sistemas de ensino público (BRASIL, 1988, 1996). 0 Plano 
Nacional de Educação (2001-2011), nos capítulos que trata dos níveis da educação, dentre as metas estabelecidas, nos remete: criar mecanismos, como conselhos ou equivalentes, para incentivar a participação da comunidade na gestão das escolas (BRASIL, 2001). 0 atual Plano Nacional de Educação 2014-2024 (Lei n. 13.005) (BRASIL, 2014) reforça a gestão democrática no artigo $9^{\circ}$, indicando que os sistemas de ensino devam disciplinar a gestão democrática do ensino público.

Com a CF de 1988, foi facultado aos municípios o direito de emitir normas e estabelecer políticas, viabilizando a implantação do regime de colaboração. Por isso, a criação das Leis referentes à institucionalização dos sistemas pressupõe o exercício de prática de autonomia e responsabilização dos atores locais (WERLE; THUM; ANDRADE, 2009; SOUZA; FARIA, 2004). 0 Sistema Municipal de Ensino é uma forma peculiar das forças locais interpretarem e inscreverem-se na educação, explicitando traços característicos e de identidades próprios, incluindo a ação na criação de estruturas institucionais, que são os órgãos normativos (Conselho Municipal de Educação) e executivos (Secretaria Municipal de Educação), focalizando a educação básica (Educação Infantil e Ensino Fundamental).

Sarmento (2005), em sua análise sobre a institucionalização dos sistemas municipais de ensino, remete-nos às seguintes reflexões, de forma a evidenciar os dois lados desse processo: i) o município tem sido apontado como um campo potencializador de experiências democráticas, pela proximidade do governo local com os sujeitos; ii) a adoção de políticas neoliberais estimulou o repasse de responsabilidades para os municípios sem considerar suas reais condições de administração. Diante desse contexto, os municípios se comprometem a universalizar o ensino básico e a reduzir as taxas de analfabetismo, bem como garantir os conhecimentos necessários à vida contemporânea, de forma que a educação se torne prioridade, com atenção voltada aos resultados da implementação de sistemas de avaliação.

Partindo dessa contextualização, este artigo traz a seguinte questão orientadora da pesquisa: o modelo de gestão educacional assumido pelo município é fator de impacto nos resultados da avaliação em larga escala, tomando como referência o Índice de Desenvolvimento da Educação Básica (IDEB) e considerando a nota das redes municipais de ensino público dos anos iniciais do ensino fundamental? Para responder a esta questão nos orientamos pelos seguintes objetivos: compreender o contexto de gestão democrática do ensino público, assim como o relevo do debate acerca da avaliação educacional; averiguar se a autonomia institucionalizada no sistema municipal de ensino tem impacto nos resultados da avaliação em larga escala, tomando como referência o IDEB, no âmbito de estado do Piauí.

A metodologia adotou atributos da abordagem qualitativa e quantitativa. É qualitativa porque propõe analisar o princípio constitucional da gestão democrática do 
ensino público e averiguar até se a autonomia tem impacto nos resultados da avaliação em larga escala. Dizemos que é também quantitativa, porque realizamos o levantamento do IDEB de todos os municípios piauienses e, nesse processo, buscamos estabelecer a relação da autonomia ou a falta desta, com o desempenho destes nas avaliações de larga escala.

A técnica de coleta de dados foi a análise documental: conjunto de 97 leis de criação dos sistemas municipais de ensino no Piauí; resultado oficial das avaliações em larga escala dos municípios piauienses (site do INEP). Consideramos a importância da análise documental em pesquisa qualitativa, seja complementando informações obtidas por outras técnicas, seja desvelando aspectos novos de um tema ou problema (LÜDKE; ANDRÉ, 1986).

Quanto à técnica de análise dos dados, adotamos os princípios da análise de conteúdo, segundo as orientações de Bardin (2009), nos orientando pelas seguintes etapas: i) pré-análise; ii) exploração do material; iii) tratamento dos resultados; iv) categorização; v) interpretação - parte em que retomamos o referencial teórico para embasar as análises, dando preferência a achados de pesquisas acerca da temática em estudo.

0 texto está organizado considerando os seguintes aspectos: organização do quadro teórico, tendo como categorias fundantes: gestão democrática do ensino público e avaliação em larga escola; levantamento de todos os municípios do Piauí, considerando a divisão geográfica por mesorregiões adotada pelo IBGE: Norte, Centro Norte, Sudeste e Sudoeste; levantamento, por mesorregiões, dos municípios com e sem sistema de ensino próprio; levantamento do IDEB de todos os municípios piauienses, organizados por mesorregiões; identificação se há diferenças e/ou semelhanças entre os municípios com e sem sistemas próprios de ensino nos resultados do IDEB. Os resultados da pesquisa empírica estão apresentados em forma de mapas, tabelas e gráficos.

\section{GESTÃO E AUALIAÇÃO EDUCACIONAL EM DEBATE}

A gestão democrática da educação tende a contribuir de forma positiva com a qualidade dos sistemas de ensino, logo com o ambiente escolar e, na esteira dessa discussão, relacionamos esta contribuição, também, com o desempenho escolar do aluno e do professor, impactando no Índice de Desenvolvimento da Educação Básica. Materializar a gestão democrática da educação implica fortalecer a participação dos sujeitos nos espaços e mecanismos de decisão sobre as políticas educacionais, significando, porém, um processo de aprendizado e de luta política, que não circunscreve aos limites da prática 
educativa, mas também a possibilidade de criação de canais de efetiva participação e aprendizado sobre democracia (DOURAD0, 2001) e democratização.

Documentos de ordem nacional têm reforçado a necessidade de legitimar o conceito de gestão democrática do ensino, a começar pela Constituição Federal de 1988, no Art. 206, ao estabelecer o princípio da gestão democrática do ensino público. Embutidos nesse princípio, podemos retirar conceitos, como: democracia, participação e autonomia, ecoados com o Estado brasileiro numa estreita relação no preâmbulo da Carta de 1988, como um valor e um resgate da dignidade humana e institucional. A LDB de 1996 trata especificamente sobre essa questão nos artigos 14 e 15: indica que os sistemas de ensino devem definir as normas de gestão democrática, recobrando a importância da participação na elaboração do projeto pedagógico da escola e a participação das comunidades em conselhos escolares; faculta aos sistemas de ensino a organização da gestão, ao tempo em que estes deverão assegurar às unidades escolares públicas progressivos graus de autonomia pedagógica, administrativa e de gestão financeira. 0 Plano Nacional de Educação (2014-2024) trata na meta 19 sobre 8 estratégicas específicas para a promoção da materialização da gestão democrática, indicando espaços e mecanismos de participação. Os documentos reforçam o debate acerca de temas, como democracia, participação, autonomia e organização de sistemas de ensino e, com o debate, emergem as dúvidas, que, segundo Nardi (2018), mais quanto ao caráter procedimental e menos político de democracia.

0 debate sobre esta matéria está longe de ser linear e consensual e, nesse sentido, nos fundamentamos em duas perspectivas defendidas por Lima (2018): a primeira, por ser a gestão democrática largamente assegurada, encontra-se também empiricamente concretizada, com maiores ou menores graus de realização; a segunda, mais do que um problema de dificuldade de democratização, se deveria partir da tese da impossibilidade, uma vez que a gestão democrática pode estar associada a um ideal normativo impraticável e inapropriado em termos de eficiência e de eficácia, de competitividade e de qualidade. Entendemos, portanto, que a capacidade da gestão democrática é fundamental para o fortalecimento do sistema e da escola, assim como para o alargamento da participação social e para o exercício da autonomia e, por essa razão, nos valemos da defesa de que capacidade, a qual nos referimos, é um processo contínuo de aprendizagem, a um só tempo, político e institucional. A ilusão da gestão democrática do ensino público pode estar associada com projetos nos moldes mercadológicos, de interesses dominantes e do capitalismo neoliberal, em nome da eficiência, da eficácia, da qualidade, da produtividade e da mercadorização de seus critérios de ação.

A possibilidade de uma gestão democrática da educação, de forma a articular com os interesses da sociedade e do Estado tem seus fundamentos, ainda que legalmente 
imperceptíveis, no modelo de administração gerencial, uma vez que as políticas educacionais são geralmente orientadas por objetivos, metas, estratégias, prazos, índice de desempenho previsto e resultados, e não muito distante, o conceito de responsabilização. Considerando esse cenário, Poli e Lagares (2017) pontuam outros termos, como regulação, governança e avaliação, os quais têm ganhado força e destaque no âmbito das políticas públicas, incluindo, obviamente, as políticas educacionais. Índices de avaliação são perseguidos e, por vezes, utilizados como parâmetro na distribuição de recursos e na adoção de medidas meritocráticas, reforçam as autoras. Trata-se de um modelo, embora amparado nos dispositivos legais como gestão democrática, orientado pela eficiência, racionalidade, produtividade e resultados contratualizados junto ao Estado, às autoridades políticas e aos stakeholders, ai se incluindo grupos que têm interesse em um modelo de educação bancária, inclusive, podendo fazer investimentos em projetos para fins de atendimento meramente econômicos.

A partir da década de 1990, o campo da educação foi marcado pela divulgação de resultados estatísticos advindos da realização de modalidade de avaliação em larga escala. Com os resultados emerge a crítica, juntamente com o discurso sobre uma política para educação dos pobres e, nesse cenário, os diagnósticos ganham destaque e os agentes estatais se empenham em ressaltar a necessidade de o governo contar com indicadores confiáveis a respeito da realidade educacional existente no país (FREITAS, 2007).

Em 1990 foi instituído o Sistema Nacional da Educação Básica (Saeb), com o caráter de traçar um diagnóstico da realidade educacional brasileira, incluindo os principais envolvidos no processo educativo e informações sobre alunos, professores, dirigentes educacionais e sistemas de ensino e, partindo dos resultados, propor políticas mais direcionadas para a eficácia da educação. Em 2007, foi criado o ĺndice de Desenvolvimento da Educação Básica (IDEB), como um indicador da avaliação da educação. Cária e Oliveira (2015), sobre gestão e avaliação da qualidade da educação, argumentam, e ao mesmo tempo fazem uma crítica, que a fim dos sistemas e das escolas atingirem índices cada vez mais elevados nas avaliações, os gestores se esforçam em atender agendas políticas, implementando estratégias de gestão muito mais mercadológicas que democráticas, diante da pressão por resultados e cumprimento de metas. Sob este argumento, Freitas (2014) explica que a educação tende a ser resolvida a partir de uma gestão eficaz, associada a termos como: tecnologias educativas, responsabilização, meritocracia e privatização, no contexto de um movimento, cuja finalidade está em reestruturar e promover o aumento da produtividade.

Assim, a prática das avaliações em larga escala (ex. Anresc/Prova Brasil; Aneb) tendem a interferir na autonomia dos docentes, influenciando a maneira como os conteúdos são ensinados (BAUER; ALAVARSE; OLIVERIA, 2015) e, por esta razão, tem levado à redução do 
currículo aos conteúdos que são cobrados na avaliação, gerando inclusive, o fenômeno do afunilamento curricular. Nessa discussão, Freitas $(2010,2014)$ reconhece que, na luta pelo controle pedagógico das escolas, o Estado acaba por ser disputado por forças sociais conservadoras, que procura imprimir, mediante avaliações externas, o controle sobre os objetivos, o conteúdo e até sobre os métodos da escola. Importante dizer que, nestas condições, a forma da avaliação existente nas escolas está, em certo sentido, ligada à forma escolar constituída pelo sistema capitalista a partir de seus objetivos educacionais.

A avaliação da educação traz consigo o discurso pedagógico, em alguma medida, orientado por organismos internacionais, a exemplo podemos citar o Banco Mundial e a OCDE, reforçando os índices do PISA. De olho nos resultados, o IDEB é acompanhado pelos gestores, pela sociedade e pelo Estado, "ou seja, um processo de cobrança e controle em cadeia." (CÁRIA; OLIVEIRA, 2015, p. 35). A crítica direcionada ao processo da avaliação externa diz respeito ao não atendimento às desigualdades sociais e educacionais e às peculiaridades locais.

Embora sob a égide de críticas, a avaliação chegou para ficar, assim, nas últimas décadas tem ganhado lugar de destaque nos debates em torno de temas, como gestão e qualidade, trazendo ao debate outro conceito: Estado avaliador ${ }^{2}$. Acompanha esse conceito pelo fato de a avaliação ser utilizada como condição de prestação de contas e de responsabilização (AFONSO, 2009), o termo accountability, contemplando ao menos duas dimensões: a de obrigação, por parte de quem presta conta; a de direito, por parte de quem solicita determinada informação; inclui também, a ideia de responsabilização e, por essa razão, prevê a atribuição de sanções ou recompensas (SCHNEIDER; NARDI, 2015). Segundo orientações de Afonso (2009), a accountability é uma ferramenta que, por um lado, exige dos governantes informações acerca da utilização dos recursos e, por outro lado, da capacidade de os cidadãos fazerem com que aqueles se responsabilizem pelas ações praticadas.

Afonso (2009, p. 15-16) nos chama a atenção de que "avaliação, prestação de contas e responsabilização nem sempre constituem elementos que se potenciem mutuamente, e nem sempre se integram em orientações e relações guiadas por uma intencionalidade democrática [...]", o que nos permite dizer que avaliação pode estar sendo guiada por mecanismos de controle, inclusive, atrelados a interesses externos e com finalidades meritocráticas e mercadológicas.

0 Estado avaliador pode assumir as seguintes características, indicando três estágios: vinculação da ideologia neoliberal às políticas de avaliação e accountability e pelo incremento de mecanismos de avaliação em larga escala em contexto nacional; aderência dos países a formas de avaliação internacional; processos de transnacionalização da prática avaliativa (AFONSO, 2013). 
Tomando como ponto de partida o cenário em que se encontra o debate em torno do conceito de gestão democrática e de avaliação da educação, reforçamos nossa inquietação no âmbito deste estudo: a autonomia dos sistemas de ensino, revelada pelo modelo de gestão democrática garantida pela CF/1988, pela LDB/1996 e pelo PNE/2014, tem impactado nos resultados das avaliações em larga escala? A gestão democrática demanda autonomia dos sistemas de ensino, de modo que estes têm competência, no sentido jurídico do termo, de organizar sua política educacional, considerando as orientações nacionais e as peculiaridades locais. Sendo assim, podemos tomar como certo que a participação, princípio legal da gestão democrática, contribui decisivamente para a melhoria no ensino e, em decorrência, para a melhoria da qualidade social da educação?

Se, a priori, não podemos afirmar a existência de uma relação direta entre gestão democrática e o Índice de Desenvolvimento da Educação Básica (IDEB), a seção seguinte se propõe a apresentar resultados de uma pesquisa realizada em municípios piauienses, de forma que tornou possível a realização de um levantamento dos municípios com sistema institucionalizado (com autonomia na gestão da educação) e sem sistema (vinculados ao sistema estadual de educação) e, a partir dos dados, nos foi possível realizar uma análise para identificar se há uma relação direta entre o modelo de gestão assumido pelo município e o IDEB (resultado da aplicação de avaliações em larga escala). Deste estudo emergiram as seguintes categorias, com as quais organizamos a seção dos resultados: cenário da pesquisa (Estado do Piauí); desenho do resultado do IDEB em municípios piauienses (por mesorregião, por mesorregião separando municípios com sistema e sem sistema; levantamento dos municípios com IDEB igual ou acima de 6,0).

\section{CENÁRIO DA PESQUISA}

0 estado do Piauí é composto por 224 municípios, dividido geograficamente, pelo IBGE em 1989, em 4 mesorregiões: Norte Piauiense, Centro Norte Piauiense, Sudeste Piauiense e Sudoeste Piauiense. Em 2017, o IBGE criou novas divisões geográficas no estado, sendo assim identificadas: regiões geográficas intermediárias e imediatas. No entanto, este estudo foi organizado considerando as mesorregiões citadas, como forma de apresentação dos dados. 


\section{Mapa 1 - Piauí em mesorregiões geográficas: Norte, Centro Norte,}

Sudeste, Sudoeste

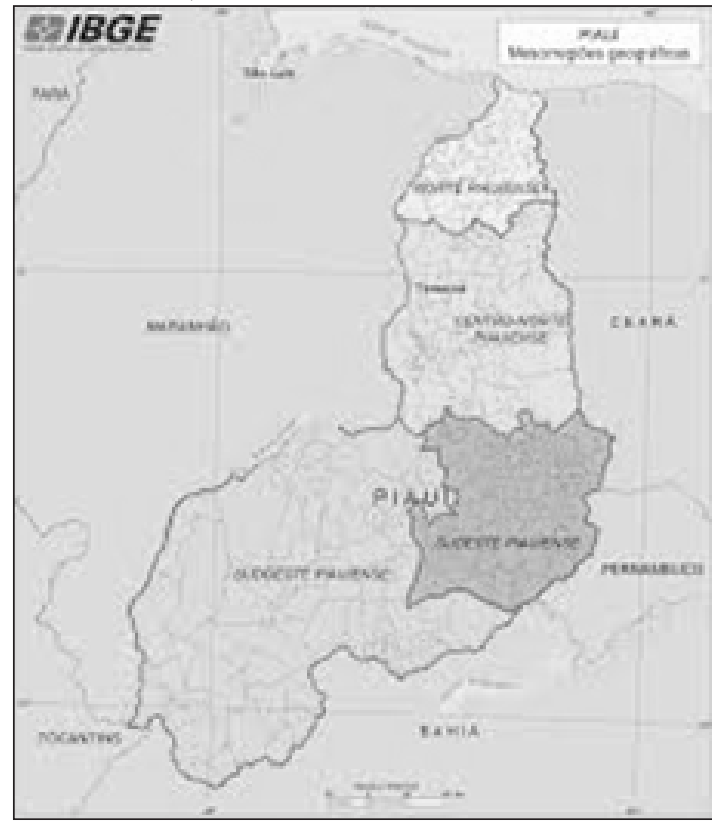

Fonte: IBGE (2011).

Tomando como referência os dados do IBGE/Censo Demográfico (2011) do Piauí, pessoas com renda per capita inferior a \$70,00: no estado (17,7\%); por mesorregião: Norte (22,8\%), Centro Norte (12,3\%), Sudeste (21,3\%), Sudoeste (22,9\%). 0 rendimento domiciliar per capita, segundo dados do IBGE (2018a) é de R\$817. Na região Nordeste, o Piaú só ganha em renda per capita por domicílio para o estado Maranhão, com renda de $\mathrm{R} \$ 605$ e o estado de Alagoas com renda de $R \$ 714$; a maior renda do Nordeste está com o estado do Rio Grande do Norte, em $R \$ 956$. Proporcionalmente, Piaui está longe de outros estados da federação, como exemplos: São Paulo, com renda de R\$1.898; Rio Grande do Sul, com renda de $R \$ 1.705$; Goís, com renda de $R \$ 1.323$. Com taxa elevada de analfabetismo, o Piauí tem $16,6 \%$ da população com idade igual ou acima de 15 anos analfabeta, enquanto a região Nordeste tem índice de $14,54 \%$ e o Brasil, índice de $6,8 \%$.

Dos 224 municípios, o Piauí tem 97 com sistema próprio de ensino, em cômputo realizado em dezembro de 2018. Este é o cenário da pesquisa, no qual foi possível identificar o Índice de Desenvolvimento da Educação Básica de cada município e, em seguida, fazer uma análise, de forma a saber se há relação entre a autonomia da gestão do ensino e os resultados das avaliações em larga escala, ou seja, se a autonomia tem impactado na qualidade da educação no âmbito do município, considerando IDEB como indicador. 


\section{GESTÃO E AUALIAÇÃO DA EDUCAÇÃO: DESENHO DO RESULTADO DO IDEB EM MUNICÍPIOS PIAUIENSES}

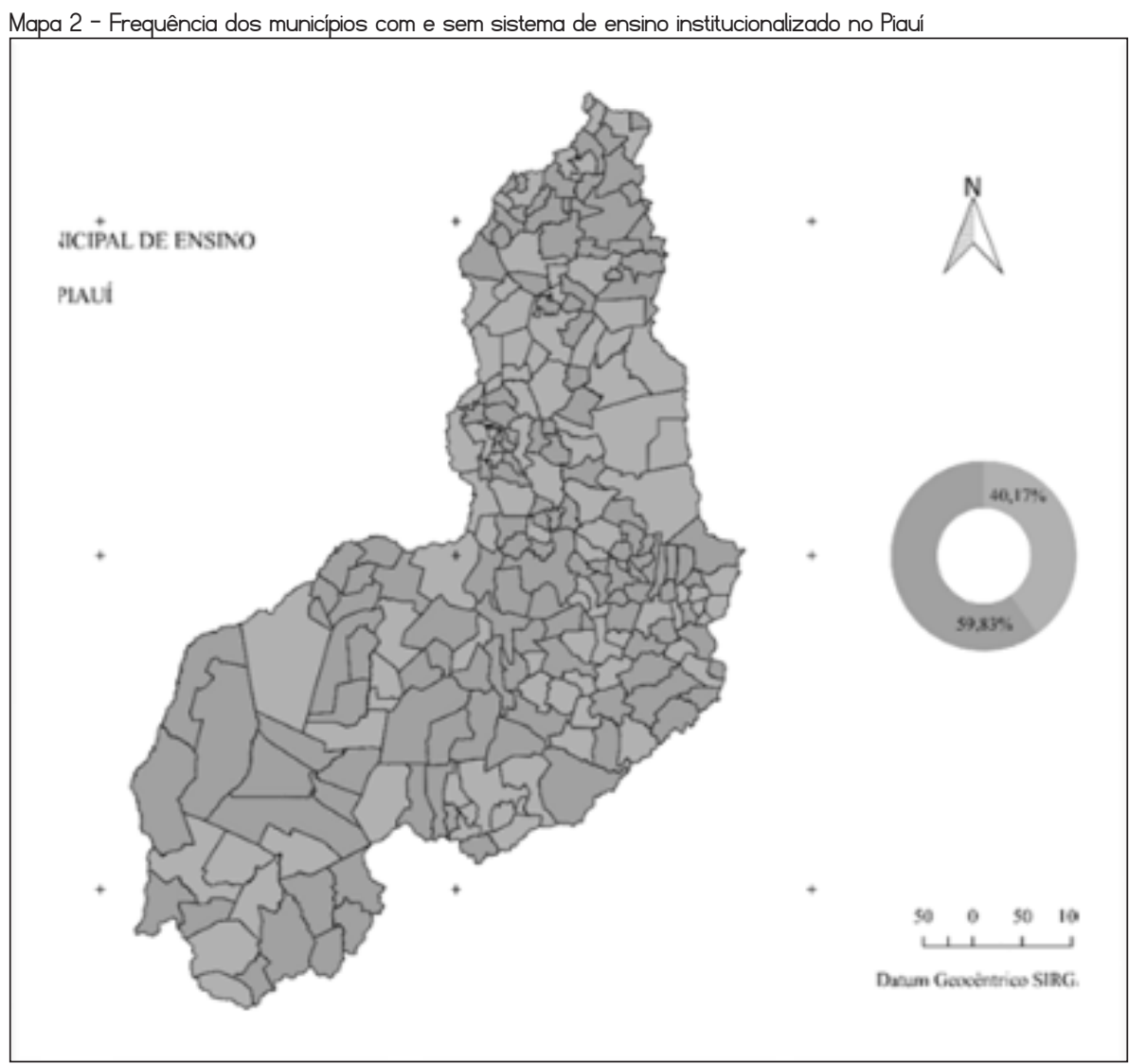

Fonte: Rede Mapa (2019).

A frequência dos municípios piauienses com sistema institucionalizado em dezembro de 2017 era de 40,17\% (90 municípios), em dezembro de 2018 a frequência subiu para 43,3\% (97 municípios), enquanto 56,7\% (127 municípios) continuam vinculados à Secretaria Estadual de Educação e ao Conselho Estadual de Educação do Piauí. Em análise do conjunto da legislação de criação dos sistemas de ensino é possivel identificar, no que se refere à organização da gestão democrática: princípios, espaços e mecanismos de participação. Os princípios tributam sobre a importância da participação nos rumos da política educacional local, os quais identificamos: participação na elaboração do Plano Municipal de Educação; 
participação na elaboração do Projeto Político Pedagógico; participação na Conferência Municipal de Educação; eleição para conselho escolar; autonomia; participação da sociedade civil; participação na elaboração do Plano Plurianual de Educação; participação na Lei de Diretrizes orçamentárias; eleição para diretor de escola; transparência; participação na elaboração do Plano de Carreira dos profissionais da educação; descentralização; liberdade de organização. Nessa discussão, apresentamos os principais espaços e mecanismos de participação identificados na legislação: Conselho Municipal de Educação; Plano Municipal de Educação; Projeto Político Pedagógico; Conferência Municipal de Educação; Conselho Escolar; Grêmios; Conselho Fiscal.

Do conjunto de 97 leis de criação dos sistemas de ensino, 35\% não fundamentam sobre a gestão democrática do ensino público, e, nessas condições, as secretarias adotam as orientações de documentos da esfera nacional, como por exemplos: a Constituição Federal/88, a Lei de Diretrizes e Bases/96, o Plano Nacional de Educação/2014-2024. No conjunto de 36 leis (35\% que tratam sobre a gestão democrática), 36,8\% dos municípios limitamse aos princípios fundamentados no Art. 14 da LDB/96; dando passos mais adiante, 63,2\% dos municípios apresentam elementos de alargamento da gestão democrática, indicando princípios além dos fundamentados no Art. 14 da LDB/96. Em um estudo realizado por Dos Santos (2013), sobre gestão democrática nos sistemas municipais de ensino de Santa Catarina, essas variáveis foram analisadas, revelando que, das 170 Leis do Sistema Municipal de Educação, $7 \%$ não fazem referência à gestão democrática; $71 \%$ estão próximas do conteúdo da LDB/96, de forma que podemos identificar certo distanciamento nos resultados, comparando os dois estudos.

Sobre o tema da avaliação em larga escala, no conjunto de 97 leis analisadas, apenas 04 (4,12\%) fazem referência à participação do município no processo nacional de avaliação. Então perguntamos: é pertinente falar de gestão democrática e qualidade da educação em uma relação direta e recíproca?

Para responder essa questão, fizemos um levantamento dos municípios piauienses com sistema institucionalizado, ou seja, com autonomia para materializar a gestão democrática, e também, dos municípios sem sistema, logo, sem autonomia para organizar sua própria gestão, porque estão vinculados às orientações da Seduc-Pl. Em seguida, fizemos o levantamento do IDEB de todos os municípios piauienses, de forma a estabelecer a relação entre gestão democrática e a qualidade da educação medida a partir das avaliações em larga escala, cujos resultados estão demonstrados por intermédio do IDEB, como podemos constatar nas tabelas e gráficos a seguir. 
Tabela 1 - Frequência dos municipios com e sem sistema de ensino e o resultado do IDEB por mesorregiões em 2017: redes municipais de ensino público e anos iniciais do ensino fundamental

\begin{tabular}{|c|c|c|c|c|c|c|c|}
\hline \multirow{5}{*}{ 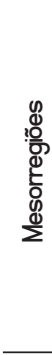 } & & $\begin{array}{l}\text { Municípios } \\
\text { com sistema }\end{array}$ & $\begin{array}{l}\text { IDEB dos } \\
\text { municípios } \\
\text { com sistema }\end{array}$ & $\begin{array}{l}\text { Municípios } \\
\text { sem sistema }\end{array}$ & $\begin{array}{l}\text { IDEB dos } \\
\text { municípios } \\
\text { sem sistema }\end{array}$ & $\begin{array}{l}\text { IDEB por Mesor- } \\
\text { região/redes } \\
\text { municipais }\end{array}$ & $\begin{array}{c}\text { IDEB } \\
\text { Piauí/redes } \\
\text { municipais }\end{array}$ \\
\hline & Norte & $11(34,4 \%)$ & 4,54 & $21(65,6 \%)$ & 4,57 & 4,55 & \multirow{5}{*}{$\underset{\sim}{\mathscr{f}}$} \\
\hline & $\begin{array}{l}\text { Centro } \\
\text { Norte }\end{array}$ & $35(54,7 \%)$ & 4,74 & $29(45,3 \%)$ & 5,02 & 4,88 & \\
\hline & Sudeste & $28(42,4 \%)$ & 4,73 & $38(57,6 \%)$ & 4,82 & 4,77 & \\
\hline & Sudoeste & $23(37,1 \%)$ & 4,19 & $39(62,9 \%)$ & 4,4 & 4,29 & \\
\hline \multicolumn{2}{|c|}{ TOTAL } & $97(43,3 \%)$ & 4,55 & $127(56,7 \%)$ & 4,7 & 4,7 & \\
\hline
\end{tabular}

Fontes: Inep (2018) e Rede Mapa (2019).

A Tabela 1 apresenta os dados relacionados à frequência dos municípios com sistema institucionalizado $(43,3 \%)$ e os municípios vinculados à Seduc-PI $(56,7 \%)$ e, na sequência, o resultado do IDEB por mesorregião, separando os municípios com sistema dos municípios sem sistema de ensino, de modo a identificar se a gestão democrática tem relação direta com o desenvolvimento da educação medida pelo IDEB. Identificamos que, grosso modo, não há diferença, que a priori, pensávamos que havia, pelo menos em termos significativos: os municípios sem sistema de ensino, logo, sem autonomia na gestão e nas políticas educacionais em âmbito local, apresentam diferença pouco significativa em relação aos sistemas institucionalizados.

Os dados da Tabela 1 nos dizem que a autonomia da gestão do ensino público está para além da letra da Lei, e o que de fato conta é o conhecimento sobre gestão democrática, vontade política dos gestores municipais, participação social, para que a opção da autogestão possa contribuir para a qualidade da educação. Estudo realizado por Martins et al. (2013), sobre a capacidade institucional de municípios paulistas na gestão da educação básica nos indica que o nosso raciocínio não é isolado. Os autores analisam a capacidade institucional no planejamento de políticas educacionais, com base em aspectos referentes à estrutura e funcionamento de sistemas, à gestão de pessoas e à gestão pedagógica, e chegam à conclusão que muitos desafios devem ser enfrentados pelos municípios pesquisados, de forma a aprimorarem sua capacidade institucional da educação básica. Alguns desses desafios citamos aqui como forma de possibilitar a reflexão sobre o comprometimento e a corresponsabilidade dos órgãos do sistema (Secretaria Municipal de Educação e Conselho Municipal de Educação) e da sociedade civil nos rumos das políticas educacionais locais: (re) orientar o funcionamento dos órgãos colegiados como mecanismos democráticos de participação efetiva; normatizar, fiscalizar e deliberar de forma mais consciente sobre as políticas públicas municipais; elaborar o Plano Municipal de Educação; contar com a participação dos profissionais da educação na elaboração do Plano de Carreira; instaurar relações 
efetivamente colaborativas entre os municípios e as demais esferas político-administrativas, com base em regulamentação legal, sem onerar as finanças municipais.

Souza e Faria (2004), em estudo sobre reforma do Estado, descentralização e municipalização do ensino ressaltam que o desafio posto ao regime de colaboração e gestão democrática se constitui da definição e consolidação de estratégias exequíveis que possam dar conta de conteúdo democrático, para que possa alicerçar suas instituições políticas e atos legais de âmbito local. Concluem que a municipalização acabou por forjar o que se pode denominar de divisão técnica e política da gestão da educação básica, rompendo com a figura solidária da colaboração. Os dados advindos da pesquisa e apresentados na Tabela 1 nos dão indicativos que a gestão democrática, da forma como propõe a municipalização do ensino, não tem conseguido se desvincular do conteúdo gerencialista, burocrático e tecnicista da administração, corroborando com um estudo realizado por Mendonça (2001), sobre Estado patrimonial e gestão democrática do ensino. Os apontamentos deste estudo nos levam a considerar que a gestão democrática é adotada pelo Estado, fortemente marcado por ordenamentos patrimonialistas, para alcançar seus objetivos estratégicos. Dados recentes de uma pesquisa realizada por Flach e Sakata (2016), sobre a gestão democrática e sua efetivação no âmbito do sistema municipal de ensino de Ponta Grossa, PR, nos contextualizam nesse cenário, ao concluir que, embora os pressupostos legais sejam amplamente discutidos na academia, sua efetivação é marcada por vinculações políticas e culturais, de forma que a participação é tutelada pelos interesses governamentais e legitima as ações dos gestores, sem, necessariamente, promover um debate realmente democrático.

Poderíamos, então, dizer com base nos dados da Tabela 1, e também nos dados dos estudos citados, que, mesmo o município com sistema de ensino institucionalizado, potencializador da gestão democrática, não tem dado conta de promover a efetiva e plena participação social? Por que a gestão democrática não tem impactado na qualidade do ensino como preveem os anseios dos dispositivos legais? 0 modelo de gestão democrática nos sistemas de ensino traduz o princípio da participação social, da descentralização, da autonomia e da corresponsabilidade na elaboração, acompanhamento e avaliação das políticas educacionais em âmbito local. Andrade (2010), em um estudo a respeito das instâncias de participação na gestão do sistema municipal de ensino do Recife, PE, analisa a construção da cultura democrática a partir da inter-relação entre as instâncias de participação envolvidas na gestão educacional. Os dados nos permitem considerar que há uma desarticulação entre os colegiados escolares, impedindo, assim, a prática dialogal e evidenciando as dificuldades para o fortalecimento da ação colegiada para além dos limites da escola. Na direção do estudo de Mendonça (2001), Andrade (2010) percebe em seus achados que o modo como os sistemas municipais de ensino têm se organizado e operado, tem-se ainda presentes práticas políticas voltadas à perpetuação do clientelismo e do patrimonialismo e, ainda, embora as instâncias de 
participação atuem em nível de desconcentração da gestão escolar e educacional, não têm conseguido intervir efetivamente nas decisões políticas do sistema de ensino.

Nossa discussão retoma o aspecto central desta pesquisa, qual seja, a relação entre o paradigma da gestão assumido por municípios piauienses e os resultados das avaliações pelo indicador IDEB. 0s dados, contrariando a hipótese inicial, de que os municípios com sistema de ensino institucionalizado teriam melhores índices de desenvolvimento da educação básica, vem nos dizer que o IDEB não apresenta, nos municípios piauienses, relação direta com o modelo de gestão. 0 baixo impacto da institucionalização nos resultados das avaliações externas, ao que nos parece, está relacionado à parca participação social nas decisões das matérias educacionais do município e, por isso, o modelo de gestão democrática, teoricamente assumido, não tem conseguido impactar na qualidade social da educação local.

Além do que está posto, precisamos considerar os limites do IDEB em relação ao retrato da qualidade a que nos referimos. Almeida, Dalben e Freitas (2013), em um estudo sobre os limites do IDEB como política de avaliação da qualidade da educação, questionam a utilização dos resultados das avaliações em larga escala como única fonte para a análise do trabalho desenvolvido pelas escolas. Pontuam que a pretensão do IDEB de sumarizar a qualidade da educação a partir do aproveitamento cognitivo e ao fluxo escolar não parece viável, já que não reflete a realidade das instituições, em especial em relação ao nível socioeconômico da população atendida. Em suas conclusões afirmam que "a utilização dos resultados das avaliações [...] tem se apresentado muito como sinônimo do trabalho desenvolvido pelas escolas, mas não se demonstra benéfica, tendo em vista que grande parte do desempenho não pode ser atribuída somente ao trabalho da/na escola." (ALMEIDA; DALBEN; FREITAS, 2013, p. 1168).

Os dados refletem uma realidade que não circunda apenas o estado Piauí, como podemos constatar no contexto do estado de Santa Catarina, a partir de um estudo realizado por Santos e Carbonera (2015) sobre gestão democrática e avaliação em larga escala. Os autores analisam como a gestão democrática e o sistema de avaliação da educação básica se expressam nos textos das leis de criação de sistemas municipais de ensino, descrevem práticas de gestão em dois municípios com IDEB diferentes e identificam que tanto as leis quanto as práticas de gestão, a partir da avaliação, ainda concentram as influências reprodutivistas e mercadológicas, por assim dizer, a maneira de conduzir a gestão da educação no município pode estar sustentada nos resultados das avaliações, na prestação de contas, no ranqueamento e na lógica da produtividade.

Uma pesquisa realizada por Buligon (2015), sobre gestão escolar e resultado do IDEB, embora no universo da escola, demonstra que para haver melhora na qualidade do ensino e nos resultados do IDEB, a escola deverá desenvolver ações para aumentar a participação da família, de forma a contribuir na construção de parcerias que favoreçam o 
sucesso escolar e social dos alunos atendidos pela instituição de ensino. Dessa forma, nossa ideia de que o envolvimento e a participação dos agentes sociais nos espaços e mecanismos do sistema de ensino continua valendo e ressaltamos, entretanto, que se é concedida a oportunidade de a sociedade civil participar nos assuntos da educação municipal, esta estratégia somente terá impacto se a participação for efetiva, responsável e comprometida com a melhoria e a qualidade social da educação. Por enquanto, constatamos que ter sistema de ensino próprio e gestão democrática na forma da lei não garante a qualidade, assim como não é determinante para a elevação do IDEB do município.

Na esteira desse entendimento, tributamos um estudo realizado por Cunha (2012), também no universo da escola, mas que condiz com nossas interpretações. 0 autor investigou sobre gestão escolar e sua relação com os resultados do IDEB em duas escolas municipais de Salvador, numa perspectiva comparada. Os resultados demonstraram realidades opostas em diversos aspectos relacionados à gestão das escolas, nas dimensões administrativoburocrática, pedagógica e política, e confirmam a relação existente entre as variáveis gestão e desempenho escolar. A gestão da escola que obteve IDEB alto se distingue, sobretudo, por haver maior participação da comunidade escolar e local, melhor controle dos resultados pela direção e forte integração e cooperação entre os professores. Na escola que obteve IDEB baixo, a gestão se caracteriza por relações informais e maior incidência de conflitos entre os profissionais, com menor participação da comunidade e controle dos resultados pela direção.

Os dados demonstram que a relação gestão democrática e o IDEB é uma questão carregada de certa complexidade e, nessa relação, as disposições legais parecem não ser suficientes para dar conta da realidade no seu contexto mais generalizado. Há uma pluralidade de opções políticas entranhadas nos sistemas municipais de ensino que nos obriga ao estudo das ações dos atores sociais e dos processos de organização da gestão e a não nos limitarmos à compreensão apenas das estruturas legais e burocráticas. Fundamentamos nossa compreensão nos achados de Lima (2002), quando argumenta que as organizações são as pessoas em interação social, de modo que os atores dispõem sempre de margem de autonomia relativa, mesmo quando a autonomia não se encontra juridicamente consagrada, formalmente reconhecida e regulamentada. Nessa perspectiva, os atores não se limitam ao cumprimento sistemático e integral das regras hierarquicamente estabelecidas por outros, não jogam apenas um jogo com regras dadas a priori, jogam, porém, com a capacidade estratégica de aplicarem seletivamente as regras disponíveis e mesmo de inventarem e construírem novas regras.

Em síntese, não são as estruturas jurídico-institucionais que determinam a organização e o bom funcionamento dos sistemas, porque elas, por si só, não garantem a autonomia e a capacidade de mudanças e avanços na educação; são as pessoas, com a vontade política, que ressignificam as normas jurídicas do sistema; são os modos de 
organização dos sistemas emergidos da prática que ressignificam as políticas organizacionais no contexto de sua aplicação; são as concepções de gestão alicerçadas nas ações colaborativas e democráticas elementos capazes de atingir os objetivos do sistema, para além dos aspectos legais, gerenciais e técnico-administrativo; o conhecimento em relação aos desafios a serem enfrentados por cada sistema permite a capacidade de um planejamento mais focado na superação dos desafios, incluindo, exclusivamente neste estudo, a avaliação externa e a consequente responsabilização tanto dos agentes internos quanto dos externos, considerando a nota aferida pelo IDEB.

0 Brasil possui metas para indicar se a educação básica está avançando ou retrocedendo e se a qualidade social está sendo alcançada. Políticas delineadas pela OCDE determinam que o Brasil, em 2021, deve atingir a nota 6,0 aferida pelo IDEB, um nível adequado comparado ao de outros países.

0 IDEB do estado do Piauí em 2017, contabilizado pelas notas das redes estadual e privada chegou à nota 5,3. A rede pública estadual somou nota 4,2, enquanto a rede privada se destacou com nota 6,3 (INEP, 2018). 0 IDEB da rede municipal (anos iniciais) foi calculado considerando a nota isolada de cada município disponibilizada pelo Inep e, em seguida, organizada por mesorregião, conforme podemos acompanhar por meio do Gráfico 1.

Gráfico 1 - Resultado do IDEB por mesorregiões (1-Norte, 2-Centro Norte, 3-Sudeste, 4-Sudoeste) do Piauí em 2017: redes municipais de ensino público nos anos iniciais

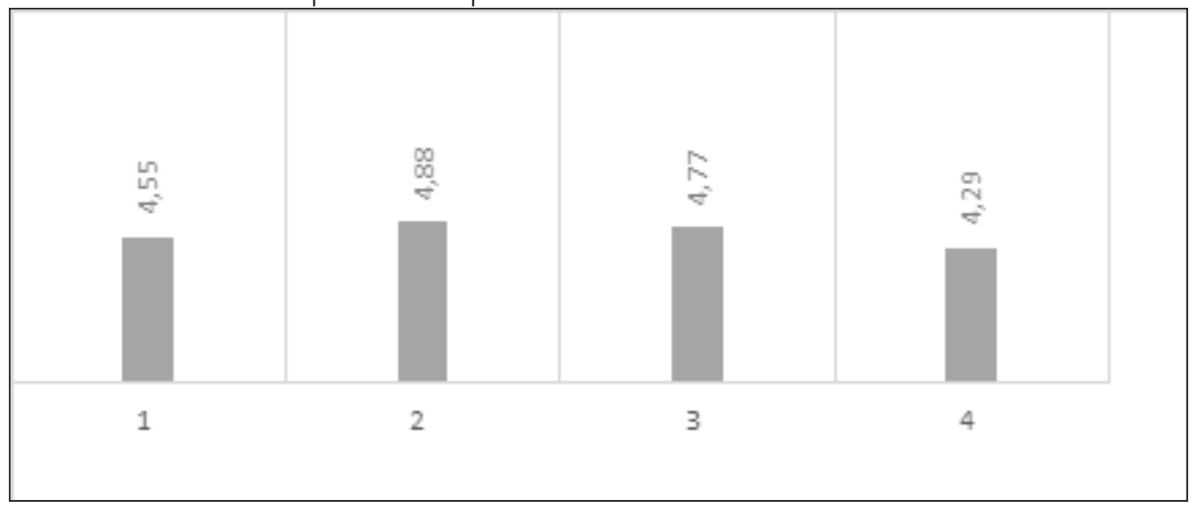

Fontes: Inep (2018) e Rede Mapa (2019).

A proposta do IDEB é mobilizar sistemas e escolas pela qualidade social da educação, de forma que o Brasil possa atingir a meta de qualidade correspondente à dos países desenvolvidos, embora os olhos dos sistemas e das escolas estejam voltados muito mais para os resultados do que para a qualidade social da educação. Os dados do Gráfico 1 nos dizem que os sistemas municipais de ensino público no Piauí precisam avançar e, para 
tanto, precisam investir na qualificação, embora o IDEB nos diga mais sobre resultado do que propriamente sobre qualidade.

Com IDEB abaixo de 5,0 - média aferida por mesorregião - dos sistemas municipais de ensino público, trazemos para a discussão a seguinte reflexão: a qualidade educacional depende de muitos fatores, incluindo, especialmente, as condições sociais, educacionais e econômicas da população. Os dados do IBGE nos levam a essa argumentação, de modo que podemos comparar: a renda per capita do estado do Piauí em 2017 está na casa de $R \$ 817$, enquanto a renda do estado de São Paulo está em $R \$ 1.898$; o IDEB da rede pública estadual do Piauí, em 2017, é 4,2 e o IDEB da rede pública estadual de São Paulo (mais elevado, embora não na mesma proporção da renda), no mesmo ano, é 5,0 (IBGE, 2018b; INEP, 2018), considerando os três níveis de ensino. Afirmamos por considerar que as condições sociais e econômicas são, também, determinantes para as condições educacionais da população. Estudo realizado por Chirinéa e Brandão (2015), embora numa perspectiva teórica, sobre IDEB como política de regulação, chegam às considerações finais dizendo que para a qualidade da educação escolar se constituir, é preciso insumos internos e externos e, que o conceito de qualidade não deveria ser reduzido somente ao desempenho escolar, tampouco ser tomado como referência para um processo de prestação de contas e para a construção de rankings. Trazem apontamentos de que é preciso integrar os resultados de desempenho escolar com os contextos intra e extraescolares, para que essa integração possa dar condições para a gestão traçar suas próprias metas e estratégias, além de definir intervenções alicerçadas na democratização e na autonomia, sem que isso signifique realizar manobras pedagógicas para atender às metas preestabelecidas pelo índice. Outro estudo que cabe nessa discussão é um realizado por Carreiro (2017), a respeito de elementos para uma educação pública de qualidade, no qual analisou indicadores educacionais publicados a partir do IDEB. Aponta como causa do fracasso escolar a inexistência de políticas públicas educacionais focadas na aprendizagem escolar; reconhece que as avaliações em larga escala têm potencialidade de subsidiar as políticas em educação com vistas à melhoria dos indicadores de qualidade do ensino e da aprendizagem, sobretudo, quando os resultados são problematizados pelos sistemas de ensino.

No contexto desta discussão, retomemos a questão inicial: o modelo de gestão educacional assumido pelo município tem impactado nos resultados da avaliação em larga escala? Sem a pretensão de darmos respostas totalizadoras para essa pergunta, apresentamos elementos que, em alta medida, estão relacionados à materialização da gestão democrática, como: opções político-institucionais do sistema de ensino que, por vezes, não sinalizam para posições políticas que denotem alargamento das condições de democratização da gestão educacional (NARDI; REBELATTO; GAMBA, 2013); as políticas educacionais que necessitam estar conectadas com as peculiaridades locais, de forma a possibilitar melhor gestão democrática (DOS SANTOS, 2013); as políticas de avaliação, em especial tratadas neste estudo, 
que estão para responder, em sua maioria, a estratégias gerencialistas de modernização e racionalização para os resultados (WERLE, 2014); a gestão democrática é adotada pelo Estado fortemente marcado por ordenamentos patrimoniais, também, para alcançar seus objetivos estratégicos (MENDONÇA, 2001). Em síntese, a gestão democrática somente terá condições de se materializar mediante garantia de efetiva e plena participação social, nos espaços e mecanismos institucionais dos sistemas e das escolas, assim como a qualidade da educação somente poderá ter relação direta com o modelo de gestão democrática se as políticas educacionais, em âmbito local, puderem contribuir com o planejamento escolar e servirem de orientação para as práticas que visem à formação cidadã do aluno e mais qualidade no ensino e na aprendizagem.

Finalizando a seção de resultados, apresentamos na Tabela 2 a relação de 13 municípios piauienses com IDEB igual ou acima de 6,0, como uma demonstração de que é possível avançar nos indicadores, apesar das condições sociais e econômicas nem sempre se mostrarem favoráveis a esse avanço.

Tabela 2 - Levantamento dos municípios com IDEB igual ou acima de 6,0 em 2017, nos anos iniciais

\begin{tabular}{|c|c|c|c|}
\hline \multirow{15}{*}{ 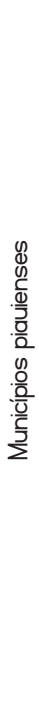 } & Nome & ldeb & Situação \\
\hline & Castelo do Piauí & 7,3 & Institucionalizado \\
\hline & Domingos Mourão & 7,1 & Integrado à Seduc \\
\hline & Oeiras & 7,1 & Integrado à Seduc \\
\hline & Pajeú do Piauí & 6,8 & Integrado à Seduc \\
\hline & Teresina & 6,8 & Institucionalizado \\
\hline & Buriti dos Montes & 6,6 & Institucionalizado \\
\hline & Bom Jesus & 6,3 & Integrado à Seduc \\
\hline & Sebastião Leal & 6,3 & Institucionalizado \\
\hline & Tanque do Piauí & 6,3 & Institucionalizado \\
\hline & Água Branca & 6,1 & Integrado à Seduc \\
\hline & Beneditinos & 6,1 & Institucionalizado \\
\hline & Lagoinha do Piauí & 6,1 & Integrado à Seduc \\
\hline & Santo Inácio do Piauí & 6,0 & Integrado à Seduc \\
\hline & Total (\%) & & $6,25 \%$ \\
\hline
\end{tabular}

Fontes: Inep (2018).

Os dados em relação aos municípios piauienses nos dizem que, praticamente, não há diferença do IDEB em relação à institucionalização da gestão democrática nos sistemas de ensino: i) por mesorregião não causa impacto e, na Tabela 2, o cenário se repete; ii) os melhores índices obtidos a partir das avaliações, ainda que sem muita expressividade, ficam a cargo dos municípios integrados ao sistema estadual de educação do Piauí; o resultado do 
IDEB pode ser atribuído a outros fatores, que não inclui de forma determinante no modelo de gestão capitaneado pelo município. Em uma pesquisa realizada por Chirinéa (2010), embora não tenha sido entre sistemas, mas entre escolas, nos permite refletir sobre a relação entre o modelo de gestão e o desenvolvimento da educação. Seu estudo, comparando duas escolas (uma com maior IDEB - 8,2, e outra com menor IDEB - 2,4), demonstrou que não somente o tipo de gestão, mas outros fatores podem influenciar na qualidade, por exemplo: o clima organizacional, o sentimento de pertencimento dos professores e a condição socioeconômica e cultural dos estudantes e de suas famílias.

Nessa direção, recorremos a outro estudo, este realizado por Werle (2008), a respeito do sistema municipal de ensino no contexto do sistema de avaliação básica. $A$ autora introduz a temática dizendo os textos de leis (leis municipais relacionadas à gestão democrática incluindo as de Sistema Municipal de Ensino, de Conselhos Municipais de Educação e de Conselhos Escolares) são entendidos como uma face das políticas e uma cristalização de interesses resultantes de inúmeros processos de negociação e disputa. Sobre a institucionalização de sistemas municipais de ensino argumenta que consolidá-lo, há que se empreender muita competência técnica, esforço político e recursos. Um elemento importante neste estudo diz respeito ao lugar do dispositivo sobre avaliação externa nas leis de criação dos sistemas municipais no estado do Rio Grande do Sul. Os dados mostram que há pouca referência à avaliação em larga escala em vigência no país, ou seja, de 184 leis analisadas, apenas $10 \%$ fazem referência clara e direta a essa questão.

Contabilizando a frequência das referências à avaliação em larga escala no corpus das leis de institucionalização dos sistemas municipais do estado do Piaú, os dados nos mostram uma estatística ainda mais baixa: dos 97 municípios institucionalizados, apenas 04 tratam sobre a avaliação em larga escala nos textos das leis que instituem os respectivos sistemas de ensino: Pau d'Arco do Piauí, Castelo do Piauí, Beneditinos e Boa Hora. Dentre estes, 2 têm IDEB igual ou superior a 6,0: Castelo do Piauí e Beneditinos (Tabela 2).

Desses 04 municípios contabilizados, Pau d'Arco do Piauí (localizado na mesorregião Centro Norte Piauiense) nos chama a atenção: explicita na Lei de institucionalização sobre a preocupação em participar do processo nacional de avaliação, objetivando a definição de prioridades e a melhoria da qualidade do ensino, no entanto, está sem nota em 2017 porque, segundo nota explicativa do Inep, não participou ou não atendeu os requisitos necessários para ter o desempenho calculado. Na situação de IDEB sem nota, temos mais 03 municípios: Milton Brandão (institucionalizado, localizado na mesorregião Centro Norte Piauiense), Aroeiras do Itaim (vinculado à Seduc-PI, localizado na mesorregião Sudeste Piauiense); Floresta do Piauí (vinculado à Seduc-PI, localizado na mesorregião Sudeste Piauiense).

Os dados reforçam nossa argumentação de que a gestão democrática de sistemas municipais de ensino, embora garantida na CF/88, na LDB/96 e no PNE/2014, encontra- 
se diante do dilema: por um lado oportunizar ao município o seu poder potencializador da democracia, da autonomia e da participação social; por outro lado vencer o desafio da gestão por resultados e da prestação de contas e de responsabilização (accountability), um modelo construído por mecanismos eficazes de controle, uma vez que a democracia no sistema capitalista não consegue pleno espaço e os processos democráticos tornam-se insuficientes e restritos no âmbito do sistema.

A utilização do modelo de accountability chega ao campo educacional, acentuando a disputa entre os países por lugares competitivos no mercado global, de forma a levar os governos a se preocuparem com os resultados dos seus sistemas escolares (SILVA; BRENNAND, 2018), um modelo, obviamente, replicado nos sistemas municipais de ensino, instabilizando os processos democráticos e fortalecendo a gestão por resultados, cuja finalidade está em aumentar a eficiência e a produtividade, aferida pela avaliação em larga escala.

\section{CONCLUSÕES}

Este estudo sobre gestão e avaliação de sistemas municipais de ensino no estado do Piauí teve como objetivo, dentre outros, identificar se há relação direta entre a autonomia do município (a partir da institucionalização da gestão democrática do ensino) e os resultados nas avaliações em larga escala aferidos pelo IDEB.

0 embasamento teórico ancorou em documentos oficiais do Estado brasileiro: CF/88, LDB/96, PNE/2014, de forma a reconhecer o lugar do princípio da gestão democrática nos sistemas municipais de ensino. Sobre a gestão democrática capitaneamos alguns elementos emergidos do debate, a saber: a gestão democrática pode estar associada a um ideal normativo impraticável em termos de qualidade; pode estar associada a um projeto nos moldes mercadológicos (LIMA, 2018); pode estar atrelada ao modelo gerencial, com vistas nos resultados.

0 sistema nacional de avaliação sofre algumas críticas, no sentido de não estar conseguindo subsidiar os municípios, de forma que estes possam melhorar a qualidade do ensino; outra crítica diz respeito ao acirramento da classificação demonstrada por meio dos rankings; está, preponderantemente, sendo utilizada como condição de prestação de contas (AFONSO, 2009).

A pesquisa empírica nos possibilitou compreender que: o estado do Piauí traz consigo sérias limitações econômicas e educacionais; parte das leis de criação dos sistemas municipais de ensino no âmbito desta pesquisa não faz referência à gestão democrática do ensino; no conjunto das 97 leis analisadas, apenas 04 fazem referência ao processo 
nacional de avaliação; o IDEB do estado, considerando as redes municipais de ensino público e os anos iniciais está na casa de 4,6; os índices por mesorregião não atinge a casa de 5,0; numa frequência de 6,25\% dos municípios identificamos IDEB igual ou superior a 6,0; dos 224 municípios, 04 não têm nota calculada, por não reunir elementos suficientes para a aplicação da avaliação; não foi possível, neste estudo, saber qual o diferencial dos sistemas de ensino, cujo IDEB é igual ou superior a 6,0, ficando em aberto como possibilidade para um estudo futuro.

0 Estado avaliador (AFONSO, 2009) expressa o lado competitivo influenciado pela lógica de mercado, por intermédio da importação do modelo gerencial do setor privado que dá ênfase a resultados. Assim, a avaliação aparece como pré-requisito para a implantação dos mecanismos da gestão da eficiência e dos resultados. Por essa razão, em conformidade com os argumentos de Afonso (2018), é muito provável que os gestores públicos (dos sistemas e das escolas) tenham uma constante preocupação em atender às regulamentações legais, às exigências hierárquicas e às demandas sociais relativas aos processos de avaliação, prestação de contas e responsabilização (três pilares fundamentais da accountability) e se confrontem, em razão disso, com dilemas e tensões decorrentes das diversas pressões e expectativas internas e externas advindas de uma pluralidade de atores (individuais e coletivos). E assim, a gestão dos sistemas de ensino vai se prestando ao mesmo papel do Estado-avaliador (da ideologia neoliberal às políticas de avaliação).

\section{REFERÊNCIAS}

AFONSO, A. J. Mudanças no Estado-avaliador: comparativismo internacional e teoria da modernização revisitada. Revista Brasileira de Educação, v. 18, n. 53, p. 267-284, abr./jun. 2013.

AFONSO, A. J. Nem tudo o que conta em educação é mensurável ou comparável. Crítica à accountability baseada em testes estandardizados e rankings escolares. Revista Lusófona de Educação, v. 13, p. 13-29, 2009.

AFONSO, A. J. 0 diretor enquanto gestor e as diferentes pressões e dilemas da prestação de contas na escola pública. Roteiro, p. 327-344, dez. 2018. Edição Especial.

ALMEIDA, L. C.; DALBEN, A.; FREITAS, L. C. de. IDEB: limites e ilusões de uma política educacional. Educ. Soc., v. 34, n. 125, p. 1153-1174, out./dez. 2013.

ANDRADE, E. F. instâncias de participação na gestão do sistema municipal de ensino: possibilidades, perplexidades no processo de democratização. Educar em Revista, n. 37, p. 293-308, maio 2010.

BARDIN, L. Análise de Conteúdo. Lisboa: Edições 70, 2009. 
BAUER, A.; ALAVARSE, 0. M.; OLIVERIA, R. P. Avaliações em larga escala: uma sistematização do debate. Educ. Pesqui., v. 41, p. 1367-1382, dez. 2015. Edição Especial.

BRASIL. Constituição. República Federativa do Brasil. Brasília, DF: Senado Federal, 5 out. 1988. Brasília, DF, 1988. Disponivel em: http://www.planalto.gov.br/ccivil_03/constituicao/constituicao.htm. Acesso em: 30 jun. 2018.

BRASIL. Lei n. 010172, de 9 de janeiro de 2001. Aprova o Plano Nacional de Educação e dá outras providências. Brasilia, DF, 9 de janeiro de 2001. Disponivel em: http://portal.mec.gov.br/arquivos/pdf/ L10172.pdf. Acesso em: 11 jan. 2019.

BRASIL. Lei n. 9.394, de 20 de dezembro de 1996. Estabelece as diretrizes e bases da educação nacional. Diário Oficial da União: Seção 1, Brasília, DF, p. 27833-27841, 21 dez. 1996.

BRASIL. Lei n. 13.005, de 25 de junho de 2014. Aprova o Plano Nacional de Educação - PNE e dá outras providências. Brasília: Presidência da República/Casa Civil/Subchefia para Assuntos Jurídicos. Diário Oficial da União, Brasilia, DF, 26 jun. 2014. Disponível em: http://www.planalto.gov.br/ccivil_03/_ato20112014/2014/lei/113005.htm. Acesso em: 11 jan. 2019.

BULIGON, K. Gestão escolar e resultado do ldeb: um estudo de caso em uma escola municipal de Sobradinho-RS. 2015. Monografia (Especialização em Gestão Educacional) - Universidade Federal de Santa Maria, Santa Maria, 2015.

CÁRIA, N. P.; OLIVEIRA, S. M. S. S. Avaliação em larga escala e a gestão da qualidade da educação. Revista de Ciências Humanas, v. 16, n. 26, p. 22-40, jul. 2015.

CARREIRO, F. B. Elementos para uma educação pública com qualidade social. Revista Educação e Emancipação, p. 169-190, 1 jun. 2017.

CHIRINÉA, A. M.; BRANDÃO, C. F. 0 IDEB como política de regulação do Estado e legitimação da qualidade: em busca de significados. Ensaio: aval. pol. públ. Educ., v. 23, n. 87, p. 461-484, abr./jun. 2015.

CHIRINÉA, A. M. 0 índice de desenvolvimento da educação básica (IDEB) e as dimensões associadas à qualidade da educação na escola pública municipal. 2010. Dissertação (Mestrado em Educação) Universidade Estadual Paulista “Júlio de Mesquita Filho”, Marília, 2010.

CUNHA, E. O. A gestão escolar e sua relação com os resultados do ldeb: um estudo em duas escolas municipais de Salvador. 2012. Dissertação (Mestrado em Educação) - Universidade Federal da Bahia, Salvador, 2012.

DOS SANTOS, A. P. Gestão democrática e inserção do sistema nacional de avaliação nos sistemas municipais de ensino de Santa Catarina. Pedagógica: Revista do Programa de Pós-graduação em Educação, v. 15, n. 31, p. 349-366, 2013.

DOURADO, L. F. A escolha de dirigentes escolares: políticas e gestão da educação no 
Brasil. In: FERREIRA, N. S. C. (org.). Gestão Democrática da Educação: atuais tendências, novos desafios. 3. ed. São Paulo, Cortez, 2001. p. 77-95.

FLACH, S. F; SAKATA, K. L. S. 0 princípio da gestão democrática na educação pública e sua efetivação no âmbito do sistema municipal de ensino de Ponta Grossa. Revista Brasileira de Política e Administração da Educação, v. 32, n. 2, p. 549-569, 1 ago. 2016.

FREITAS, D. N. T. Avaliação e gestão democrática na regulação da educação básica brasileira: uma relação a avaliar. Educ. Soc., v. 28, n. 99, p. 501-521, maio/ago. 2007.

FREITAS, L. C. de. A avaliação para além da "forma escola". Educação: Teoria e Prática, v. 20, n. 35, p. 89-99, jul./dez. 2010.

FREITAS, L. C. de. Os reformadores empresariais da educação e a disputa pelo controle do processo pedagógico na escola. Educ. Soc., v. 35, n. 129, p. 1085-1114, out./dez. 2014.

IBGE. Censo demográfico 2010: retratos do Brasil e do Piauí. Brasília, DF: IBGE, 2011.

Disponivel em: http://www.lbge.gov.br/home/presidencia/noticias/pdf/ censo_2010_piaui.pdf. Acesso em: 6 ago. 2019.

IBGE. Censo demográfico: cidades e estados. [S. l.] IBGE, 2018a. Disponivel em: https://www.ibge.gov. br/cidades-e-estados/se.html. Acesso em: 20 ago. 2019.

INEP. Ideb: resultados e metas. [S. l]: IBGE, 2018b. Disponível em: http://ideb.inep.gov.br/resultado/resultado/resultado.seam?cid=4931806. Acesso em: 20 ago. 2019.

LIMA, C. L. Modelos organizacionais de escola: perspectivas analíticas, teorias administrativas e o estudo da ação. In: MACHADO, L. M.; FERREIRA, N. S. C. (org.). Política e gestão da educação: dois olhares. Rio de Janeiro: DP\&A, 2002. p. 33-53.

LIMA, L. C. Por que é tão difícil democratizar a gestão da escola pública? Educar em Revista, v. 34, n. 68 , p. 15-28, mar./abr. 2018.

LÜDKE, M.; ANDRÉ, M. E. D. A. Pesquisa em educação: abordagens qualitativas. São Paulo: EPU, 1986.

MARTINS, A. M. et al. A capacidade institucional de municípios paulistas na gestão da educação básica. Cadernos de Pesquisa, v. 43, n. 150, p. 812-8350, 01 dez. 2013.

MENDONÇA, E. F. Estado patrimonial e gestão democrática do ensino público. Educação \& Sociedade, v. 22, n. 75, p. 84-108, 1 ago. 2001.

NARDI, E. L. Gestão democrática do ensino público na educação básica: dimensões comuns e arranjos institucionais sinalizados em bases normativas de sistemas municipais de ensino. Educar em Revista, v. 34, n. 68 , p. 123-136, mar./abr. 2018. 
NARDI, E. L.; REBELATTO, D. M. B.; GAMBA, I. C. Opções político-institucionais de sistemas municipais de ensino: para onde caminha a gestão democrática do ensino público? Roteiro, v. 38, n. 1, p. 169-194, 2013.

POLI, L.; LAGARES, R. Dilemas da gestão democrática da educação frente ao contexto da Nova Gestão Pública. RBPAE, v. 33, n. 3, p. 835-849, set./dez. 2017.

REDE MAPA. Frequência dos municípios piauienses com e sem sistema próprio de ensino público. [S. l.]: Banco de dados da Coordenação do Piaui/Universidade Estadual do Piauí, 2019.

SANTOS, A. P.; CARBONERA, V. Gestão democrática expressa nos sistemas municipais de ensino no contexto da avaliação em larga escala. EDUCERE, p. 40249-40262, 26-29 out. 2015.

SARMENTO, D. C. Criação dos sistemas municipais de ensino. Educ. Soc., v. 26, n. 93, p. 1363-1390, set./ dez. 2005.

SCHNEIDER, M. P.; NARDI, E. L. Accountability em educação: mais regulação da qualidade ou apenas um estágio do estado avaliador? ETD Educ. Temat. Digit., v. 17, n. 1, p. 58-74, jan./abr. 2015.

SILVA, P. F. da; BRENNAND, E. G. de G. Políticas de Accountability na gestão educacional do estado de Pernambuco - Brasil. RBPAE, v. 34, n. 1, p. 233-251, jan./abr. 2018. D0l: 10.21573/vol34n12018.75088.

SOUZA, D. B. de; FARIA, L. C. M. de. Reforma do estado, descentralização e municipalização do ensino no Brasil: a gestão política dos sistemas públicos de ensino pós-LDB 9.394/96. Ensaio: Avaliação e Políticas Públicas em Educação, v. 12, n. 45, p. 925-944, 1 dez. 2004.

WERLE, F. O. C. Panorama das políticas públicas na educação brasileira: uma análise das avaliações externas de sistemas de ensino. Revista Lusófona de Educação, v. 27, n. 27, p. 159-180, 2014.

WERLE, F. 0. C. Sistema municipal de ensino: contexto do sistema de avaliação da educação básica. ANPED, GT-05: Estado e Política Educacional, 2008. Disponível em: http://www.anped.org.br/sites/default/files/gt05-4716-int.pdf. Acesso em: 6 set. 2019.

WERLE, F. O. C.; THUM, A. B.; ANDRADE, A. C. Processo nacional de avaliação o rendimento escolar: tema esquecido entre os sistemas municipais de ensino. Ensaio: Avaliação e Políticas Públicas em Educação, v. 17, n. 64, p. 397-420, jul./set. 2009.

Endereço para correspondência: Avenida Dom Pedro II, 629, 64980-000, Corrente, Piaú, Brasil; raicribeiro@hotmail.com 